\title{
CONTEXTO HISTÓRICO DA FORMAÇÃO DO PROFESSOR BACHAREL EM CIÊNCIAS CONTÁBEIS PARA A DOCÊNCIA NO ENSINO SUPERIOR E O DESENVOLVIMENTO DA PROFISSIONALIDADE DOCENTE
}

\author{
Marlene de Oliveira Soares Portela ${ }^{1}$ \\ Josania Lima Portela Carvalhêdo ${ }^{2}$
}

\begin{abstract}
Resumo
O presente artigo é uma revisão bibliográfica que tem por objetivo refletir acerca da importância da formação pedagógica para o magistério no ensino superior e da profissionalidade docente, desencadeando base teórica que afirme a importância e a pertinência do conhecimento pedagógico-didático em seu caráter mediador para a prática pedagógica no Bacharelado em Ciências Contábeis. A abordagem teórica que contextualiza a docência no ensino superior revela como, historicamente, no ensino da Contabilidade, os professores são recrutados entre profissionais de sucesso na profissão cuja maioria está despreparada para o magistério, e sem o domínio das questões pedagógicas, há ausência dos conhecimentos pedagógicos necessários ao exercício da docência na Educação Superior. Atualmente, essa problemática foi agravada pelo fato de que, com a expansão desse nível de ensino, além de profissionais não habilitados para o magistério, estão ingressando os que também não possuem experiência profissional na área contábil, restringindo os conhecimentos ao currículo do curso de formação inicial. A reflexão teórica ressalta a complexidade da docência, que envolve diversas dimensões: humana, técnica, política e ética, e a necessidade do desenvolvimento da profissionalidade docente que pressupõe consciência, compreensão e conhecimento. A fim de assimilar os papéis requeridos para os professores na configuração e no desenvolvimento do currículo no Ensino Superior, entre as conclusões deste estudo está a legitimação da natureza teórico-prática da profissão docente que pressupõe a existência de um corpo de conhecimentos em função dos quais se questione a ação docente.
\end{abstract}

Palavras-chave: Formação docente. Curso de Ciências Contábeis. Docência no Ensino Superior. Desenvolvimento da profissionalidade docente.

\section{HISTORICAL CONTEXT OF THE ACCOUNTING PROFESSOR TRAINING FOR HIGHER EDUCATION AND THE DEVELOPMENT OF TEACHING PROFESSIONALISM}

\begin{abstract}
This article is a literature review that aims to reflect about the importance of pedagogical training for teaching at higher education and the teaching professionality, grounded on a theoretical basis that allows the recognition of the importance and relevance of the pedagogical-didactic knowledge due to its mediative character for the teaching practice at the Accounting Bachelor's course. The theoretical approach that contextualizes teaching in higher education reveals how historically, in the teaching of Accounting, professors have been recruited among successful professionals and mostly are unprepared to professional teaching for having no pedagogical knowledge due to the lack of pedagogical skills which are mandatory in Higher Education. Currently, this problem is compounded by the fact that with the expansion of this level of education non-qualified professionals professors who have no professional experience in the area of the course have been hired restricting the curricula knowledge in the initial formation course. The theoretical reflection shows the complexity of teaching which involves several dimensions: human, technical, political and ethical, besides the necessity to develop the teaching profession that requires awareness, understanding

\footnotetext{
${ }^{1}$ Mestranda do Programa de Pós-Graduação em Educação - PPGEd, da Universidade Federal do Piauí - UFPI e Servidora do Centro de Ciências da Saúde - CCS/UFPI. E-mail: mathelipe@ gmail.com

${ }^{2}$ Doutora em Educação pela Universidade Federal do Ceará- UFC, professora associada da Universidade Federal do Piauí - UFPI - Centro de Ciências da Educação do Departamento de Métodos e Técnicas de Ensino - DMTE e do Programa de Pós-Graduação em Educação - PPGEd. E-mail: josaniaportela@gmail.com
} 
and knowledge. In order to understand the roles required for professors in the configuration and development of higher education curricula among which are the findings of this study is the recognition of theoretical and practical nature of the teaching profession that presupposes the existence of a knowledge corpus that questions the teaching action.

Keywords: Teaching training. Accounting bachelor's course. Higher education teaching. Development of the teaching professionality.

\section{Para iniciar: contextualizando o objeto de estudo}

Diante da especificidade do trabalho docente, a formação de professores para o exercício da docência na Educação Superior tem sido alvo de estudos de teóricos como Masetto (2015), Pimenta e Anastasiou (2014), Vasconcelos (2000), Veiga e Viana (2009), dentre outros, que analisam mais detalhadamente a prática pedagógica dos professores que atuam nesse nível de ensino, e que, muitas vezes, não possuem formação pedagógica para o desempenho da função docente.

Leite e Ramos (2010) chamam a nossa atenção para a contradição presente no contexto universitário, visto que as Instituições de Ensino Superior, como espaços de formação profissional para a docência na Educação Básica, aceitam a condição não profissional da docência universitária, pois não exigem formação pedagógica para o ingresso no Magistério Superior dos candidatos bacharéis. Dessa forma, as instituições de ensino superior compreendem que há conhecimentos específicos para o exercício da docência na Educação Básica ao ofertar os cursos de licenciatura cursos de formação de professores para as diversas áreas do conhecimento -, mas não exigem dos seus profissionais para atuar no magistério superior uma formação pedagógica.

Apesar da presença de profissionais sem a formação adequada ser comum no âmbito de cursos de graduação, principalmente nos bacharelados, nos últimos anos, temos observado uma massificação da Educação Superior em nome da democratização do seu acesso, sendo criadas inúmeras instituições de ensino superior em todo o País, com o advento do que as políticas denominam de expansão do ensino superior, motivando a contratação de profissionais de diversas áreas do conhecimento para compor o quadro de docentes das faculdades, dos institutos e das universidades, seja na esfera privada, seja na pública.

A expansão provocou uma crescente contratação de profissionais sem a devida qualificação pedagógica para atuar no magistério. Para cursos superiores das mais diversas áreas do conhecimento, dentre os quais, o de Ciências Contábeis, são contratados bacharéis para atuar em sala de aula, sem formação pedagógica para o exercício da docência, pois esses profissionais não contaram, na sua formação inicial, ou mesmo na continuada, bem como nos cursos de mestrado e doutorado específicos da área de atuação, com uma formação pedagógica para atuação no magistério, resultando, muitas vezes, no comprometimento da qualidade do ensino. 
Assim, se por um lado há garantia dos conhecimentos técnicos dos conteúdos do curso em que atuam, pois, fundamentados em suas práticas, podem contribuir com conhecimentos extraídos de sua profissão e articulá-los com as teorias estudadas, por outro lado, faltam-lhes conhecimentos pedagógicos ou do fazer pedagógico.

Sendo a docência marcada pela complexidade, requer formação para fundamentar a ação dos professores que passam pela formação inicial e continuada. Nosso objeto de estudo abrange a formação inicial dos professores, bacharéis em Ciências Contábeis, que desempenham a docência no Ensino Superior. Portanto, o presente artigo, objetiva refletir acerca da importância da formação pedagógica para o magistério no ensino superior e da profissionalidade docente, desencadeando base teórica que afirme a importância e a pertinência do conhecimento pedagógico-didático em seu caráter mediador para a prática pedagógica no Bacharelado em Ciências Contábeis.

Dessa forma, na perspectiva da consecução do objetivo proposto, estruturamos o presente texto em três seções, além da seção introdutória e da seção conclusiva. Na introdução apresentamos a problemática e o objetivo do estudo, como também a estrutura do texto. Na primeira seção delineamos a trajetória histórica do Curso de Ciências Contábeis, mostrando o surgimento da profissão no contexto da sociedade capitalista brasileira, o seu desenvolvimento e o exercício da docência na área contábil em uma realidade histórica que não requer formação pedagógica.

$\mathrm{Na}$ seção seguinte buscamos apresentar aspectos históricos da formação de professores no Brasil, descrevendo como ela se desenvolveu tendo como lócus as escolas normais, embora no ensino superior houvesse predominância dos profissionais liberais que não possuíam formação pedagógica para atuar na docência. Em continuidade, a seção imediata trata da construção da profissionalidade docente no ensino universitário, partindo da compreensão do conceito para colocar a necessidade da superação da racionalidade da tradição acadêmica que se apoia no pressuposto de que ensinar se aprende na prática, demonstrando a necessidade de saberes que fundamentem a ação docente.

Por último, trazemos a seção conclusiva em que, com base na discussão estabelecida, enfatizamos que não há a exigência legal de formação pedagógica para atuação no magistério superior, entretanto este fato não torna os conhecimentos específicos da docência menos necessários ou importantes, gerando a sua ausência dilemas na configuração do currículo no ensino superior e na prática pedagógica do profissional docente. 


\section{O bacharel em Ciências Contábeis e o exercício da docência}

A Contabilidade, no Brasil, tem pouco mais de um século. Segundo Sacramento (1998), a primeira escola especializada em Contabilidade, no país, data de 1902, portanto, do início do Século XX, pensada a partir de uma necessidade utilitarista das instituições, do comércio, dos banqueiros, entre outros segmentos econômicos, de profissionais de escrituração contábil no contexto da sociedade capitalista.

De acordo com Iudícibus, Martins e Carvalho (2005), desde o seu surgimento, com status de simples método de escrituração, até a sua maturação como ciência genuinamente social aplicada, de forte cunho econômico, a ênfase da Contabilidade sempre foi nas questões práticas. Entretanto, na compreensão dos autores essa função utilitarista potencializa as especulações teóricas como ciência.

Antes de 1950, conforme Nossa (1999), eram escassos os cursos de Contabilidade no país, mas a expansão do Ensino Superior vem sendo considerável desde essa década, com maior ênfase nas últimas décadas do século XX e início do século XXI. Esse crescimento, segundo o teórico, aconteceu na forma quantitativa, sem preocupação com os aspectos qualitativos. Assim, aumentaram-se apenas as instituições, os cursos e as vagas, sem preocupação com a formação dos formadores dos cursos de graduação.

Com o crescimento quantitativo do ensino superior, acentuado nas últimas décadas, o descaso com a questão pedagógica evidenciou-se de forma assustadora. Além dos profissionais mais experientes e estabelecidos na profissão, jovens profissionais passaram a exercer a docência na educação superior sem nenhum preparo para o exercício do magistério e sem a experiência no exercício da profissão (NOSSA, 1999).

De acordo com Nossa (1999), historicamente, no ensino da Contabilidade, os professores são recrutados entre profissionais de sucesso na profissão que, em sua maioria, estão despreparados para o magistério, não tendo domínio das questões pedagógicas, ou seja, há ausência dos conhecimentos pedagógicos necessários ao exercício da docência na Educação Superior. Entretanto, esses profissionais com larga experiência no exercício da sua profissão, possuíam o conhecimento da área e do fazer contábil.

Verificamos, portanto, que desde a implantação, os currículos dos cursos superiores de bacharelado são voltados para o exercício de determinada profissão, em que o interesse era instruir e formar profissionais com competência e conhecimento em determinada área, sendo que a escolha dos profissionais formadores dessas áreas estava condicionada ao sucesso obtido na profissão, como se o êxito profissional pudesse ser transferido aos seus alunos. Hoje, porém, além de profissionais 
não habilitados para o magistério, estão ingressando os que não possuem sequer experiência profissional na área do curso, restringindo os conhecimentos ao currículo do curso de formação.

Essa realidade histórica é promotora de uma depreciação quanto à importância da habilitação pedagógica para o exercício da docência. Esse aspecto foi ressaltado por Pimenta e Almeida (2011), quando enfatizam que há uma compreensão de que, para a atuação no contexto da docência, os profissionais necessitam reproduzir o que realizam na atuação profissional na área específica, rememorar suas experiências como aluno e recorrer aos saberes sedimentados ao longo do exercício da própria docência.

A palavra docência tem sua origem no latim docere, que significa ensinar, instruir, mostrar, indicar, dar a entender. Para Veiga e Viana (2009), refere-se ao trabalho dos professores. Estes na Educação Superior são responsáveis pela formação de profissionais nas diversas áreas de atuação profissional e, neste contexto, mais especificamente na área contábil. Para isso, é necessário haver profissionais não só com conhecimentos, aptidões e atitudes éticas relativas a cada profissão, mas também com os conhecimentos pedagógicos necessários ao exercício da docência.

Ao concluir o curso de graduação na área contábil, o bacharel que se aventura no magistério superior não compreende a profissão docente como uma carreira que possui as suas especificidades que, assim como a sua formação básica, requer fundamentação teórica, estratégias de ensino e competência pedagógica. Ensinar, portanto, é uma atividade complexa e mobiliza conhecimentos gerais e específicos.

Dessa forma, segundo Pimenta e Anastasiou (2014), muito embora os professores universitários bacharéis possuam experiências importantes e fundamentação teórica profunda na área base de formação, há um despreparo predominante e um desconhecimento do processo de ensinar e aprender.

As autoras apontam várias dimensões da formação docente: profissional, pessoal e organizacional. Na primeira dimensão, a profissional insere os elementos definidores da ação docente, ou seja, os requisitos profissionais; a segunda dimensão se refere aos requisitos pessoais relativos ao comprometimento com a docência e as experiências; e, a organizacional, estabelece as condições de viabilização do trabalho e os objetivos a alcançar com a atuação individual.

Para Masetto (2015), o domínio na área pedagógica envolve sete eixos: conceito de processo ensino-aprendizagem, em que o professor precisa ter claro o que significa ensinar e aprender; professor como produtor e gestor do currículo, tornando essencial o conhecimento a fim de orientar as atividades propostas de forma a tornar a sua prática pedagógica competente; integração das disciplinas como componentes curriculares que em conjunto contribuem para a formação 
profissional; relações estabelecidas entre professor-aluno e aluno-aluno no processo educativo; teoria e prática da tecnologia educacional, tornando o processo ensino-aprendizagem mais eficaz e eficiente; processo avaliativo na perspectiva formativa, fornecendo informações relevantes para a tomada de decisão de forma a garantir a aprendizagem; e, por último, o planejamento como atividade educacional e política. Os eixos propostos pelo autor permitem que o professor aprofunde seus conhecimentos sobre o processo educativo e possa agir com maior segurança, fazendo as escolhas necessárias para a garantia de uma educação com qualidade.

De acordo com Vasconcelos (2000), o exercício da docência na educação superior exige do bacharel contábil: o conhecimento, em profundidade, do campo do saber que pretende ensinar; que seja crítico; que tenha conhecimento da realidade que o cerca a fim de selecionar os conteúdos (conceituais, factuais, procedimentais e atitudinais) necessários para formação de profissionais coerentes com o contexto social; e, ainda, que seja capaz de produzir novos conhecimentos.

Sabemos que o desenvolvimento profissional dos professores é considerado um processo contínuo, ordenado e reflexivo, envolvendo a formação inicial. Os bacharelados não se formam para a docência, mas fornecem os conhecimentos da área base de formação, a formação continuada e a formação advinda da própria atividade docente em que os professores aprendem pela própria experiência vivida.

Dessa forma, ao se considerar a articulação teoria-prática, é importante considerar que o processo de desenvolvimento profissional do docente, de acordo com Garcia (1999), é um fenômeno complexo e diversificado. A formação pedagógica tem atribuição fundamental no processo de tornar-se professor na Educação superior a fim evitar que, sem a formação específica para atuação na docência, o professor seja apenas reprodutor de modelos presentes em sua formação, mas que possam ser capazes de introduzir mudanças necessárias, a fim de atender às necessidades formativas da sociedade em constante transformação.

Sem dúvida, a formação inicial é requisito importante por consolidar as bases necessárias para a profissão em destaque, embora para o exercício da docência, a formação inicial seja marcada por lacunas em relação aos saberes da profissionalização docente (pedagógicos). Diante da ausência da formação pedagógica, os professores da área contábil enfrentam situações conflituosas - pelo fato de o ato de ensinar ser atividade complexa e laboriosa - quando no desenvolvimento de sua atividade profissional há a exigência de tomada de decisão racional, o que significa compreender as razões de determinadas ações geradas pela singularidade do ato de ensinar.

Embora a atividade docente seja complexa e laboriosa como enfatizamos, na seção seguinte, descrevemos os aspectos históricos da formação de professores no Brasil, revelando como 
historicamente, para o ingresso na profissão docente dos professores bacharéis no ensino superior, a exigência se resume ao domínio dos saberes na área específica de atuação profissional.

\section{Aspectos históricos da formação de professores no Brasil}

Segundo Gatti e Barretto (2009), para refletir acerca da formação de professores no Brasil, os interessados não podem desconsiderar o fato de que a expansão do ensino teve início nos fins dos anos 1970, de forma a alcançar as camadas da população menos favorecidas social e economicamente.

A escolarização no Brasil foi durante séculos apanágio das elites, em que pese a existência de propostas educacionais em documentos e estudos, em debates entre teóricos, filósofos, políticos e religiosos, e em algumas poucas escolas, porém sem um correspondente em política inclusiva da população como um todo na escola (GATTI; BARRETTO, 2009, p. 11).

A ampliação da oferta de Educação Básica no País e o advento da expansão industrial e do capital refletem, consequentemente, na Educação Superior provocando a abertura de novas salas de aula para formação dos profissionais de forma a atender a Escola Básica e aos setores econômicos que demandam por profissionais qualificados das mais diversas áreas, por conseguinte, fazendo crescer a demanda por professores para a formação desses profissionais, tanto nas licenciaturas como nos bacharelados. Dessa feita, segundo as autoras, a formação de professores é impactada com o crescimento das redes (pública e privada) de ensino:

[...] Crescimento recente em face da história da escolarização em outros países, e crescimento vertiginoso em pouco mais de 40 anos, a considerar os dados da demografia educacional no Brasil. Esse crescimento do sistema escolar foi sem dúvida um mérito, provindo de grande esforço social, político e de administração, porém é chegado o momento de se conseguir que esse sistema tenha melhor qualidade em seus processos de gestão, nas atuações dos profissionais e nas aprendizagens pelas quais responde. Um dos aspectos a se considerar nessa direção, entre outros, é a formação dos professores, sua carreira e perspectivas profissionais (GATTI; BARRETTO, 2009, p. 12).

Segundo as autoras, a ampliação das redes de ensino foi uma conquista importante, tomando a luta pela educação a partir de então outra direção, ou seja, deixa de ser relativa ao quantitativo e passa a ser referente à qualidade do ensino, incidindo, nesta perspectiva, na formação de professores em todos os níveis de ensino. Mas, como são formados os profissionais da educação superior? Como suprir as demandas pelos profissionais docentes para atuar no ensino superior? Para atuar nos cursos de licenciatura, esses profissionais são oriundos dos cursos dessa modalidade, que lhes oferecem a fundamentação para o exercício da docência, embora reconheçamos que há 
especificidades na docência nesse nível de ensino que abrange as dimensões ensino, pesquisa e extensão. Podemos inferir que a sua formação inicial e os cursos de formação continuada exigidos na atuação docente na educação superior - mestrado e doutorado - fornecem os saberes essenciais para o exercício da docência nesse nível de ensino.

Mas o que dizer dos professores bacharéis, caso do curso de Ciências Contábeis? Apenas os saberes da profissão são necessários ao exercício da docência na educação superior? A sua vivência enquanto aluno no mesmo curso capacita para o exercício da profissão docente? Sabemos que: "ensinar é algo que qualquer um faz em qualquer momento, não é o mesmo que ser professor [...]" (FLODEN; BUCHMANN apud GARCIA, 1999, p. 24, grifos do autor).

Ser professor requer saberes para a gestão do ensino, pois, de acordo com Pimenta e Anastasiou (2014, p. 143), “[...] as questões de sala de aula, de aprendizagem e de ensino, de metodologia e de avaliação são de sua responsabilidade". Para que as escolhas sejam realizadas racionalmente, o professor, além de saber ensinar, deve saber justificar as suas opções e ações, ou seja, o porquê faz e da forma como faz.

Ademais, na academia, o processo de organização do ensino ainda se dá de forma individualizada. Constituindo-se, assim "[...] um processo de trabalho solitário, extremamente individual e individualizado; o professor é deixado à sua própria sorte e, se for bastante prudente, evitará situações extremas nas quais fiquem patentes as falhas em seu desempenho" (PIMENTA; ANASTASIOU, 2014, p. 143).

Historicamente, o ingresso na profissão docente para os professores bacharéis ocorria em decorrência da "[...] reconhecida competência profissional do convidado na área de atuação específica, relacionada à disciplina que irá atuar" (PIMENTA; ANASTASIOU, 2014, p. 142).

O pressuposto é de que, por dominar a área profissional relacionada ao curso, “[...] o profissional já possui em si condições suficientes para ser ele um transmissor e que, nesse contexto, ensinar é dizer um conteúdo a um grupo de alunos reunidos em sala de aula" (PIMENTA; ANASTASIOU, 2014, p. 142).

Portanto, segundo Garcia (1999, p. 72), “[...] a institucionalização da formação de professores é um processo paralelo ao desenvolvimento dos sistemas nacionais de educação e de ensino [...]”, que demandou por profissionais para atuação no magistério. Assim, a formação de professores ocorreu a partir de uma demanda estabelecida no contexto social.

No Brasil, de acordo com Aranha (1996), o ofício de professor teve início com a chegada dos jesuítas e permaneceu sob o comando da Companhia de Jesus até a sua expulsão de Portugal e de seus domínios no século XVIII. Nóvoa (1995, p. 15), analisando a história da profissão docente, ressalta que essa “[...] desenvolveu-se de forma subsidiária e não especializada, constituindo uma 
educação secundária de religiosos ou leigos das mais diversas origens [...]", fato que aconteceu no Brasil, com os religiosos assumindo a função de professores.

Com a expulsão da Companha de Jesus, o ensino no Brasil Colônia, segundo Aranha (1996), ficou a cargo dos profissionais leigos, sem nenhuma organização e de caráter fragmentado, não havendo preocupação com a formação do profissional docente. Esse quadro se modificou com a chegada da Família Real portuguesa ao Brasil, em 1808, pois, segundo o autor, esse fato provocou a criação de várias instituições e foram implantadas as primeiras ações com vistas à educação superior de caráter pragmático, visto que havia a necessidade de formação de militares, engenheiros, médicos, destinados à aristocracia brasileira.

Não houve, entretanto, investimento nos ensinos primário e secundário. Aranha (1996) revela que os profissionais que atuavam no ensino eram improvisados e geralmente desempenhavam outra atividade paralela para sobreviver. $\mathrm{O}$ ensino formal básico só ganhou alguma atenção do Estado após a Independência do Brasil, em 1889. Mesmo assim, o estabelecimento de um sistema educacional nacional só ocorreu por meio do Ato Adicional, de 12 de agosto de 1834.

Segundo Brzezinski (1996), no Brasil, até a década de 1930, a formação de profissionais para o magistério estava restrita às escolas normais, formando o professor primário. Essas escolas apresentavam sérios problemas que comprometiam o seu funcionamento e perpassavam também pela questão da formação dos formadores.

Nóvoa (1995, p. 15) afirma que, embora diante de todas as fragilidades existentes nas escolas normais, elas constituíram um espaço de excelência na formação de professores, pois "[...] mais do que formar professores (a título individual), as escolas normais produzem a profissão docente (em nível coletivo), contribuindo para a socialização dos seus membros e para a gênese de uma cultura profissional".

Entendemos que a constituição da profissão professor começou a ser delineada no contexto das escolas normais, embora, paradoxalmente, muitos dos professores que ali atuavam na formação de outros profissionais do ensino fossem profissionais liberais, não possuíssem formação pedagógica adequada para o exercício da docência.

Secundo Monlevade (1997), no Brasil, foi apenas no final da Primeira República (1889 1930) que começaram a surgir as faculdades que agregavam as áreas de Filosofia, Ciências e Letras, a fim de formar profissionais licenciados para atuar nos cursos secundários, reflexo da Reforma Francisco Campos (Decreto n. 21.241/1932) e da Reforma proposta por Capanema, em 1942 (Lei Orgânica do Ensino Secundário), no Governo de Getúlio Vargas, em decorrência da necessidade 
das escolas secundárias comporem os seus quadros de pessoal com profissionais qualificados a fim de ser formalmente reconhecidas.

Azevedo (1976) reconhece o avanço em relação à formação de professores imputado pelas reformas de 1932 e 1942. Essas reformas surgiram em decorrência do Movimento da Escola Nova no Brasil, a partir da qual, segundo Aranha (1996), educadores introduziram o pensamento liberal democrático com o ideal de escola pública para todos, na busca da construção de uma sociedade igualitária.

Em decorrência desses movimentos em favor da educação no País, segundo Aranha (1996), a Universidade de São Paulo (USP) foi organizada em 1934, como resultado da aglutinação de diversas faculdades isoladas, tais como a de Filosofia, de Ciências e de Letras.

Esses movimentos tiveram reflexos ainda na aprovação da Lei de Diretrizes e Bases da Educação Nacional (Lei n. 4.024, de 21 de dezembro de 1961) que marcou a década de 1960 no país. Essa lei trouxe mudanças para os diversos níveis e para as várias modalidades de ensino, especialmente para a Educação Superior. Preconiza a Lei, no seu artigo 52, que as universidades são instituições pluridisciplinares de formação dos quadros profissionais de nível superior, de pesquisa, de extensão e de domínio e cultivo do saber humano e, ainda, requerendo que "[...] um terço do corpo docente, pelo menos, com titulação acadêmica de mestrado e doutorado".

Em sequência, temos a Lei da Reforma Universitária, de 1968, Lei n. 5540/1968, período do Regime Militar no Brasil. Segundo Antunes, Bandeira e Silva (2011, p. 1), essa lei teve dois princípios norteadores: o controle político das universidades públicas brasileiras e a formação de mão de obra para atender às demandas do sistema econômico.

Quanto à formação de professores, a Lei da Reforma Universitária “[...] obrigava, também, a criação de uma unidade voltada para a formação de professores para o ensino secundário e de especialistas em questões pedagógicas - a Faculdade (ou centro ou departamento) de Educação" (LOPES; FARIA FILHO; VEIGA apud ANTUNES; BANDEIRA; SILVA, 2011, p. 2).

Dando sequência, a Lei do Ensino de $1^{\text {o e }} 2^{\circ}$ graus de 1971, Lei n. 5.692/1971, estabeleceu a formação docente para atuação nesses níveis. Portanto, na educação básica, a formação em licenciaturas de $1^{\circ}$ grau e os estudos adicionais, a ser ministrados nas universidades e demais instituições que mantenham cursos de duração plena, podendo também ser ministrados em comunidades menores, em faculdades, centros, escolas, institutos e outros tipos de estabelecimentos criados ou adaptados para esse fim, com autorização e reconhecimento na forma da lei. Como não era seu objetivo, a referida lei não trata da carreira para o Magistério Superior. 
Gatti e Barretto (2009, p. 38-39), fazendo um resumo da formação de professores no contexto da Lei n. 5.692/1971, destacam:

O suprimento de professores para uma rede de ensino que crescia não estava garantido à época, e essa lei, na previsão de que não haveria docentes suficientes para o atendimento das demandas dos sistemas educacionais em virtude da ampliação do ensino obrigatório para oito anos e, sobretudo, da necessidade de expansão da oferta de classes de $5^{\mathrm{a}}$ a $8^{\mathrm{a}}$ séries, criava, em caráter suplementar, várias possibilidades de se suprir a falta de docentes formados em cursos de licenciaturas (arts. 77 e 78). Além disso, seu texto mantinha em vigor os esquemas emergenciais de habilitação ao magistério, os chamados Esquemas I e II, respectivamente para $1^{\mathrm{a}}$ a $4^{\mathrm{a}}$ séries e para $5^{\mathrm{a}}$ a $8^{\mathrm{a}}$ séries.

Conforme apontam as autoras, esta Lei garantia que, não havendo oferta de professores habilitados para atender às necessidades do $1^{\circ}$ e $2^{\circ}$ graus, era permitido em caráter suplementar e a título precário professores sem a devida habilitação. Ainda que, não havendo licenciados, os profissionais bacharéis das diversas áreas puderam ser registrados no Ministério da Educação e Cultura mediante complementação de estudos que incluía a formação pedagógica, segundo critérios estabelecidos pelo Conselho Federal de Educação.

Na sequência, a Lei n. 7.044/82, que alterou o artigo 30 da Lei 5.692/71, manteve "[...] a formação na habilitação magistério, mas [introduziu] outras opções formativas para os docentes dos anos iniciais e finais do Ensino fundamental" (GATTI; BARRETTO, 2009, p. 39).

Por sua vez, de acordo com a atual Lei de Diretrizes e Bases da Educação Nacional (LDBEN), pós-redemocratização do País, Lei n. 9.394/1996, a formação do professor para o Magistério Superior, conforme dispõe o Artigo 66, deve ocorrer em cursos de pós-graduação Stricto sensu, prioritariamente em cursos de mestrado e doutorado, haja vista a necessidade de formação de profissionais pesquisadores, fomentando o desenvolvimento científico e o fundamento metodológico que rege o ensino neste nível: a articulação entre o ensino, a pesquisa e a extensão.

Mas a formação em cursos de pós-graduação stricto senso embora proporcione a formação de pesquisadores, não garante a formação pedagógica do professor do magistério superior e, assim, o desenvolvimento da profissionalidade docente, o que trataremos na seção a seguir.

\section{A profissionalidade docente no ensino universitário}

Compreendemos profissionalidade como "[...] conjunto de atributos, socialmente construídos, que permitem distinguir uma profissão de outros muitos tipos de actividades, igualmente relevantes e valiosas" (ROLDÃO, 2005, p. 108). Com base nesse entendimento, podemos afirmar que a profissão docente no ensino superior exige, para o seu exercício, capacidades e saberes. Dentre os saberes, aqueles vinculados às práticas pedagógicas em tempo e espaço determinados. 
Segundo Leite e Ramos (2010, p. 30), em busca da profissionalidade docente, é preciso “[...] superar a ideia pré-concebida de que para ensinar basta conhecer o conteúdo da área curricular a que o docente se encontra vinculado, ter talento, ter bom senso, seguir a intuição, ter experiência e cultura $[. .] ”$, para compreender a complexidade e a especificidade da profissão, visto que:

Toda ação educativa é estruturada e sustentada por uma racionalidade; os saberes diversos que sustentam uma decisão prática e que servem para justificar uma intervenção educativa são articulados pelo professor. Este de alguma forma sabe justificar o que faz e apresentar argumentos que expressam sua compreensão de um determinado fenômeno ou modo de agir. [...] O rumo da ação que o docente desencadeia corresponde a uma articulação de saberes e de conhecimentos que dão sustentação à sua tomada de decisão de intervenção no contexto de ensino (THERRIEN, 2012, p. 119).

O autor enfatiza que toda prática pedagógica é fundamentada por uma teoria que permite ao professor planejar a sua ação, tomando decisões para o desenvolvimento do currículo, de forma a alcançar os objetivos propostos. Para isso, o professor toma decisões conscientes sustentadas por uma racionalidade, mobilizando os saberes para uma prática pedagógica competente.

Dessa feita, é preciso superar a racionalidade da tradição acadêmica da docência no ensino superior que se limita ao domínio do conteúdo da área específica - saber disciplinar (GUATHIER et al., 1998) - e/ou a experiência prática na área da formação - saberes experienciais (GUATHIER et al., 1998) - com base no pressuposto de que ensinar se aprende na prática (ação docente). Não estamos negando, com essa afirmação, a importância da experiência profissional, ou seja, no exercício da profissão docente, como em qualquer outra profissão, há a construção dos saberes experienciais, mas ressaltando a importância dos saberes pedagógicos que possam fundamentar a reflexão na e sobre a ação, como orienta Schön (1992), possibilitando a fundamentação e o redimensionamento da ação docente, visto que a prática sem uma fundamentação teórica que a sustente, resulta em ofício, como alertamos anteriormente.

Ademais, a docência é uma atividade complexa que abrange várias dimensões: humana, técnica, política e ética, que não podem ser compreendidas de forma isolada, mas como parte de um todo. Barbosa e Oliveira (2009, p. 1744), em relação à dimensão humana da docência, compreendem que essa "[...] se expressa nos aspectos afetivos/ emocionais, de valor/respeito e de relações pessoais/interpessoais e sociais, articulados de maneira complexa e não conectados apenas entre si $[\ldots]$ ".."

Portanto, a dimensão humana não pode ser considerada de forma isolada das outras dimensões, ao tempo em que não deve ser subestimada, mas a sua interferência “[...] nas relações pedagógicas em sala de aula, visto que a interação e as relações interpessoais, pessoais e sociais 
carregam em si intencionalidade que levará ou não, dependendo da qualidade desta relação, ao comprometimento com a educação de boa qualidade" (BARBOSA; OLIVEIRA, 2009, p. 1745) deve ser compreendida.

Superando a concepção prescritiva da atividade docente, a dimensão técnica possibilita a organização e a gestão do trabalho pedagógico pela “[...] compreensão do caráter mediador do conhecimento pedagógico-didático, que, por ser estruturante, não oferece soluções, mas possibilita encontrar meios de agir na ação pedagógica docente" (LEITE; RAMOS, 2010, p. 32).

Quanto à dimensão política da docência, pode ser compreendida na perspectiva da sua intencionalidade, pois, como enfatiza Freire (2004), toda ação educativa é uma forma de intervenção no mundo. Como experiência humana, portanto, não é neutra, mas traz subjacente sua ideologia na perspectiva da conservação, reprodução ou transformação social, sendo, ao mesmo tempo, determinada e determinante do contexto social e cultural em que se insere.

A dimensão ética tem relação com a autonomia docente que pressupõe opções e compromissos assumidos no desenvolvimento da sua prática pedagógica, pois, segundo Sacristán (1999, p.45), [...] "ainda que atuemos em contextos predeterminados que nos condicionam, cada ação é sempre radicalmente única e incorpora a necessidade de orientar-se por critérios [...]" sempre na perspectiva da qualidade da educação.

A construção dos fundamentos da profissão docente, em relação à dimensão humana, técnica, política e ética, ocorre no desenvolvimento da profissionalidade a partir do reconhecimento da sua natureza teórico-prática, pressupondo "[...] a existência de um corpo de conhecimentos em função dos quais se questione a acção docente e as interacções que no seu quadro vão ocorrendo" (LEITE; RAMOS, 2010, p. 32).

É importante ressaltar que o desenvolvimento da profissionalidade diz respeito a "[...] um processo sistemático que se orienta pelo desenvolvimento pessoal, profissional, individual e coletivo dos docentes cujo objetivo último é melhorar a aprendizagem do aluno e a renovação e melhoria contínua da escola" (MOYA, 2006, p. 17).

O desenvolvimento da profissionalidade docente pressupõe " [...] consciência, compreensão e conhecimento" (CUNHA apud LEITE; RAMOS, 2010, p. 32), requerendo investimento pessoal relativo às trajetórias individuais, coletivas vinculadas às construções do grupo de trabalho desenvolvidas no ambiente laboral e institucional, que diz respeito ao investimento das instituições na formação do seu quadro docente.

A docência é profissão e como profissão é aprendida “[...] a partir de declarações públicas e não por simples aprendizagem imitativa" (BOURDONCLE apud LEITE; RAMOS, 2010, p. 33), 
como acontece com os ofícios. Nesse sentido, as autoras estabelecem a diferença entre profissão e ofício: a primeira requer uma certificação pública da capacidade teórico-prática para o seu exercício e a segunda resulta da aprendizagem prática, sem fundamento teórico que respalde a ação.

Além da consciência, a questão da profissionalidade docente implica perceber o caráter mediador do conhecimento pedagógico-didático, estruturante da ação docente, oferecendo subsídios ao professor a fim de eleger metodologias adequadas a cada situação de aprendizagem, considerando, entre outros elementos, o público, o conteúdo, os objetivos, de forma que as abordagens sejam epistemologicamente circunscritas (LEITE; RAMOS, 2010).

Ademais, os saberes são mobilizados para atendimento das demandas requeridas pela prática pedagógica, e "[...] a docência universitária reclama requisitos que vão além dos relativos aos campos disciplinares a que cada docente se encontra vinculado.” (LEITE; RAMOS, 2010, p. 35).

Entretanto, é preciso considerar também que as instituições de ensino superior são "[...] espaços de formação singular [...]”, e que a mediação pedagógica não pode ser dissociada dos projetos formativos de cada "[...] área de formação em que os indivíduos se situam e das especificidades epistemológicas que os delimitam” (TRINDADE, 2010, p. 75).

O conhecimento pedagógico-didático é

[...] possibilitador de uma leitura presente e decorrente da acção docente, que corresponde tanto a um conhecimento que o norteia, como o que se produz na ação, enquanto campo que trata do fenómeno educativo. [...] vem assumindo o papel mediador no processo de (re) construção e (re) significação do conhecimento profissional docente universitário, nomeadamente sendo propositivo e referente, e não apenas prescritivo e normativo (LEITE; RAMOS, 2010, p. 35).

Está relacionado, portanto, segundo as autoras, aos fazeres docentes, porém, diferente de uma receita, o conhecimento teórico que sustenta as reflexões sobre a ação pedagógica, nessa perspectiva, possibilita o planejamento da prática pedagógica que envolve a dimensão política e organizacional, sua análise com base nos pressupostos e nas concepções teórico-metodológicas adotadas e o redimensionamento a partir dos resultados obtidos, desenvolvendo investigações na e da prática pedagógica como meio de ressignificação teórico-metodológica, incorporando inovações e construindo novos conhecimentos a partir de uma prática concreta, ainda, considerando que "[...] os modos de trabalho pedagógico configuram-se de acordo com as diversas esfericidades dos campos disciplinares" (LEITE; RAMOS, 2010, p. 39), sendo responsabilidade do professor os procedimentos de planificação, a transposição didática e a avaliação da aprendizagem, na mediação entre o objeto do conhecimento e o aluno.

Nessa ordem, de acordo com Trindade (2010), supera a função prescritiva da ação docente, de caráter universal, independente das propriedades do objeto do saber e dos sujeitos envolvidos, 
considerando as características cognitivas, afetivas, emocionais e valorizando as experiências e os saberes dos alunos, propondo a formação do sujeito autônomo, consciente do seu projeto de formação, conforme os saberes especializados da área.

Segundo Leite e Ramos (2010), para pensar a profissionalidade docente é preciso compreender os papéis requeridos para os professores na configuração e no desenvolvimento do currículo na academia e reconhecimento da natureza teórico-prática da profissão docente que pressupõe a existência de um corpo de conhecimentos em função dos quais se questione a ação docente quanto às interações entre sujeito/conhecimento e sujeito/sujeito.

Por fim, buscamos, na última seção deste texto, trazer as conclusões acerca da reflexão proposta sobre a importância da formação específica para o magistério e da profissionalidade docente, legitimando a importância e a pertinência do conhecimento pedagógico-didático em seu caráter mediador para a prática pedagógica.

\section{E para concluir...}

A partir da reconstrução histórica do percurso de formação docente por meio das leis brasileiras, retomamos o nosso objeto de estudo: a formação do professor bacharel em Ciências Contábeis, para concluir que não há na legislação regras específicas quanto à formação pedagógica para atuação no magistério superior.

A obrigatoriedade da Lei de Diretrizes e Bases da Educação Nacional - LDB vigente para atuar no Ensino Superior é a formação em cursos Stricto sensu, ou seja, mestrado e doutorado, o que não assegura a formação da dimensão pedagógica docente, embora importante para a formação de pesquisadores, no atendimento às dimensões que devem abranger a educação superior: ensino, pesquisa e extensão.

Há, portanto, necessidade de formação de mestres e de doutores para o ensino superior. Entretanto, esse fato não torna os conhecimentos específicos da profissionalização docente menos importantes, pois, a docência no magistério superior exige um conjunto de comportamentos, conhecimentos, destrezas, atitudes e valores que constituem a especificidade de ser professor (SACRISTAN, 1995).

Com base na realidade da formação de professores delineada e nos referenciais teóricos que a fundamentam, nossa pesquisa de mestrado em educação, no Programa de Pós-Graduação em Educação da Universidade Federal do Piauí, objetiva analisar os dilemas enfrentados pelos professores bacharéis em Ciências Contábeis na educação superior acerca do desenvolvimento da prática pedagógica. Compreendemos, portanto, que a ausência de formação pedagógica para 
fundamentar teoricamente a ação docente no exercício do magistério no âmbito da educação superior faz esses profissionais vivenciarem dilemas na sua prática pedagógica.

Pressupomos a necessidade do desenvolvimento da profissionalidade docente a partir da compreensão dos papéis requeridos para os professores na configuração e no desenvolvimento do currículo no ensino superior e do reconhecimento da natureza teórico-prática da profissão docente, que requer conhecimentos em função dos quais se fundamenta a ação docente.

Ao apresentar a trajetória histórica da docência no ensino superior, especificamente relacionada ao curso de Ciências Contábeis, e os aspectos históricos da formação de professores no Brasil, verificamos como vem sendo negada a importância da formação específica para o magistério superior e do desenvolvimento da profissionalidade docente. Revela, o debate aqui proposto, a partir dos vários teóricos que foram chamados a dialogar, que o bacharel, ao se aventurar na docência no ensino superior, deve compreender a complexidade da profissão, o que exige uma formação que possa subsidiar a tomada de decisão racional, compreendendo os seus fundamentos e se apropriando dos saberes necessários a sua ação educativa, dada a pertinência do conhecimento pedagógico-didático em seu caráter mediador para a prática pedagógica competente.

\section{Referências}

ANTUNES, I. C. B.; BANDEIRA, T. S.; SILVA, R. O. A Reforma Universitária de 1968 e as transformações nas instituições de ensino superior. In: XIX SEMANA DE HUMANIDADES, 19, 2011, Natal/RN. Anais da XIX Semana de Humanidades. Natal, RN: Universidade Federal do Rio Grande do Norte, 2011. p. 01-10.

ARANHA, M. L. de A. História da Educação. 2. ed. São Paulo: Moderna, 1996.

AZEVEDO, F. de. A transmissão da cultura. Brasília: Melhoramentos, 1976.

BARBOSA, A. M.; OLIVEIRA, C. C. Dimensão humana da formação docente. In: IX CONGRESSO NACIONAL DE EDUCAÇÃO - EDUCERE, 9, 2009, Curitiba/PR. Anais do IX Congresso Nacional de Educação. Curitiba: Pontifícia Universidade Católica do Paraná, 2009.p. 1739-1753.

BRASIL. Lei n. 4.024, de 20 de dezembro de 1961. Fixa as Diretrizes e Bases da Educação nacional. Disponível em: 〈http://www.senado.gov.br/legislacao〉. Acesso em: 4. jun. 2015.

Lei n. 5.540, de 28 de novembro de 1968. Fixa normas de organização e funcionamento do ensino superior e sua articulação com a escola média, e dá outras providências. Disponível em: <http://www.senado.gov.br/legislacao>. Acesso em: 4. jun. 2015.

Lei n. 5.692/71, de 11 de agosto de 1971. Fixa as Diretrizes e Bases para o $\mathbf{1}^{\mathbf{0}}$ e $\mathbf{2}^{\mathbf{o}}$ graus, e dá outras providências. Disponível em: 〈http://www.senado.gov.br/legislacao〉. Acesso em: 4. jun. 2015. 
. Lei n. 7.044/82, de 18 de outubro de 1982. Altera dispositivo da Lei n. 5.692, de 11 de agosto de 1971, referente à profissionalização do ensino de $2^{\circ}$ grau. Disponível em: <http://www.senado.gov.br/legislacao>. Acesso em: 4. jun. 2015.

Lei n. 9.394, de 20 de dezembro de 1996. Fixa as Diretrizes e Bases da Educação nacional. Disponível em: <http://www.senado.gov.br/legislacao>. Acesso em: 4. jun. 2015.

BRZEZINSKI, I. Pedagogia, pedagogos e formação de professores: busca e movimento. Campinas, SP: Papirus, 1996.

FREIRE, P. Pedagogia da Autonomia: saberes necessários à prática educativa. 29. ed. São Paulo: Paz e Terra. 2004.

GARCIA, M. C. Formação de professores: para uma mudança educativa. Porto, PT: Porto, 1999.

GATTI, B. A.; BARRETTO, E. S. de S. Professores do Brasil: impasses e desafios. Brasília: UNESCO, 2009.

GUATHIER, C. et al. Por uma teoria da pedagogia: pesquisas contemporâneas sobre o saber docente. 2. ed. Ijuí: Ed. UNIJUÍ, 1998.

IUDÍCIBUS, S. de; MARTINS, E.; CARVALHO, N. Contabilidade: aspectos relevantes da epopeia de sua evolução. Revista Contabilidade Financeira, São Paulo, n. 38, p. 7-19, maio/ago. 2005.

LEITE, C.; RAMOS, K. Questões da formação pedagógico-didática na sua relação com a profissionalidade docente universitária. In: LEITE, C. Sentidos da Pedagogia no Ensino Superior. Porto: Legis, 2010. p. 29-43.

MASETTO, M. T. Competência pedagógica do professor universitário. São Paulo: Summus, 2015.

MONLEVADE, J. Educação pública no Brasil: contos e descontos. Ceilândia: Ideia, 1997.

MOYA, J. L. M. La profesión docente y la construcción del conocimiento professional. Buenos Aires: Magistério del Rio de la Plata, 2006.

NOSSA, V. Formação do corpo docente dos cursos de graduação em contabilidade no Brasil: uma análise crítica. Caderno de Estudos, São Paulo, FIPECAFI, n. 21, p. 1-20, maio/ago. 1999.

NÓVOA, A. Profissão professor. Porto, PT: Porto, 1995.

PIMENTA, S. G.; ALMEIDA, M. I. (Org.). Pedagogia universitária: caminhos para a formação de professores. São Paulo: Cortez, 2011.

ANASTASIOU, L. G. C. Docência no ensino superior. São Paulo: Cortez, 2014.

ROLDÃO, M. do C. N. Profissionalidade docente em análise - especificidades do ensino superior e não superior. Nuances: estudos sobre educação - ano XI, v. 12, n. 13, p. 105-126, jan./dez. 2005.

SACRISTAN, J. G. Consciência e ação sobre a prática como libertação profissional dos professores. IN: NÓVOA, A. (Org.). Profissão professor. Porto, PT: Porto, 1995. p. 63-92. 
SACRAMENTO, C. O. de J. O ensino de teoria da contabilidade no Brasil. Caderno de Estudos, São Paulo, n. 18, p. 1-10, maio/ago. 1998.

SCHÖN, D. Formar professores como profissionais reflexivos. IN: NÓVOA, A. (Coord.). Os professores e a sua formação. Lisboa, PT: Dom Quixote, 1992. p. 77 - 91.

THERRIEN, J. Docência profissional: a prática de uma racionalidade pedagógica em tempos de emancipação de sujeitos. In: D’ÁVILA, C. M.; VEIGA, I. P. A. (Org.). Didática e docência na educação superior. Campinas, SP: Papirus, 2012. p. 109- 132.

TRINDADE, R. O ensino Superior como espaço de formação. In: LEITE, C. Sentidos da Pedagogia no Ensino Superior. Porto: Legis, 2010. p. 75-98.

VASCONCELOS, M. I. C. A formação do professor do ensino superior. São Paulo: Pionera, 2000.

VEIGA, I. P. A.; VIANA, C. M. Q. Q. Docentes para a educação superior: processos formativos. Campinas: Papirus, 2009.

Recebido em: 15/02/2016 Aceito em: 27/06/2016 